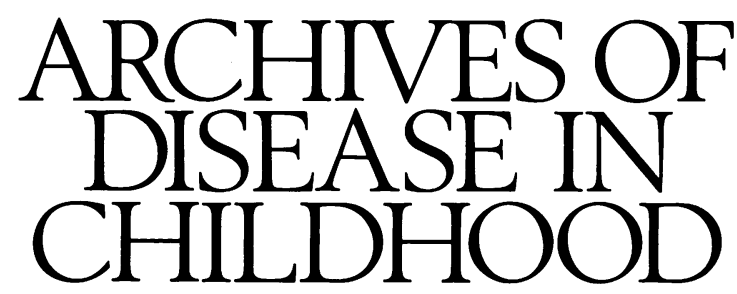

The fournal of the British Paediatric Association

\title{
Annotations
}

\section{Diabetes in puberty}

Successful treatment of type I insulin-dependent diabetes (IDDM) is of particular importance during puberty for the achievement of normal growth and sexual maturation and to reduce the risk of long term microvascular complications. Yet, with the onset of puberty, glycaemic control as judged by serial glycated haemoglobin $\left(\mathrm{HbA}_{1}\right)$ concentrations, may deteriorate. ${ }^{1-3}$ This deterioration is often attributed to the psychological problems of adolescence and poor compliance with diet and insulin dosage. ${ }^{45}$ However, over the last few years it has become clear that this is not the complete explanation and that the endocrine changes of puberty may also contribute to the poor glycaemic control, disordered growth and sexual maturation in IDDM.

\section{Insulin resistance during puberty}

Normal pubertal development is associated with dramatic changes in insulin sensitivity and fasting insulin concentrations rise during puberty reaching a peak in both sexes at stage 3 and 4 before declining and returning to prepubertal values during early adult life. ${ }^{6}$ Furthermore, during puberty the plasma insulin responses to both oral and intravenous glucose are greater than those observed in younger children or adults. ${ }^{78}$ Using the hyperinsulinaemic clamp technique Amiel et al $^{9}$ showed an appreciable reduction in insulin stimulated glucose metabolism in pubertal compared with prepubertal and adult subjects which resulted from decreased glucose uptake in muscle rather than any change in hepatic glucose production rates. ${ }^{10}$ Similar changes of insulin sensitivity can be demonstrated in adolescents with IDDM. As in normal subjects, insulin resistance is maximal in late puberty but at every stage of puberty diabetics are more insulin resistant than controls.

\section{Growth hormone}

In their studies, Amiel et al demonstrated a correlation between changes in insulin sensitivity and mean growth hormone concentrations. ${ }^{9}$ Puberty is characterised by an increase in growth hormone pulse amplitude, ${ }^{11}$ and mean overnight growth hormone concentrations rise during puberty being maximal in mid to late puberty corresponding to the changes in insulin sensitivity. ${ }^{12}$ Some authors have noted an earlier rise in growth hormone concentrations in girls ${ }^{13}$ corresponding to the earlier pubertal growth spurt whereas sex differences in the timing of changes in insulin sensitivity have not been consistently demonstrated. ${ }^{14}$ is

In adolescents with IDDM, plasma growth hormone profiles are characterised by an increase in both pulse amplitude and baseline concentrations. ${ }^{13}$ Growth hormone excess has been shown to impair the ability of insulin to suppress hepatic glucose production and to stimulate peripheral glucose uptake. ${ }^{16}{ }^{17}$ Direct evidence that these high growth hormone concentrations are responsible for the increased insulin resistance during puberty in IDDM has largely been gathered from studies of the dawn phenomenon. In subjects with IDDM insulin requirements increase overnight and are maximal between 8.00-9.00 am. The extent of this overnight change in insulin sensitivity can be correlated with mean growth hormone concentrations and it is reversed after suppression of growth hormone secretion. ${ }^{18} 19$ The dawn phenomenon is maximal at puberty stage 3-4 in both sexes, ${ }^{18}$ but there is considerable variation between and within individuals which leads to major problems targeting insulin treatment during puberty.

\section{Failure of current insulin regimens}

Although it has long been recognised that insulin requirements in IDDM rise during puberty, increases of insulin doses of up to 1.5 units $/ \mathrm{kg} /$ day only lead to marginal improvements in $\mathrm{HbA}_{1}$ concentrations. ${ }^{20}$ It could be argued that greater increases are necessary but current insulin regimens do not permit appropriate insulin delivery overnight. ${ }^{21}$ Even where the long acting insulin is given late at night as part of a multiple injection treatment, free insulin concentrations tend to be high during the early part of the night and then wane as the night proceeds. The over insulinisation during the early part of the night can lead to a high incidence of unrecognised hypoglycaemia, ${ }^{22}$ and the low concentrations of insulin during the latter part of the night often fail to control the dawn rise in blood glucose concentrations.

The failure to achieve appropriate insulin concentrations overnight may also lead to an increase in growth hormone secretion. Hyperinsulinaemia during the early part of the night may stimulate growth hormone secretion directly ${ }^{23}$ or as part of a counter-regulatory response to hypoglycaemia. ${ }^{24}$ Low concentrations of insulin during the latter part of the night lead to a decrease in insulin-like growth factor I (IGFI) bioactivity with a resulting feedback drive for further growth hormone secretion. The role of insulin in the regulation of the growth hormone/IGF-I axis in IDDM has only recently been elaborated. Despite high growth hormone concentrations, serum concentrations of IGF-I tend to be low in IDDM. This growth hormone resistance may be 
the result of inadequate portal delivery of insulin as insulin has a permissive role in growth hormone receptor function. The major IGF-I binding proteins (IGFBP-3, IGFBP-1) are also altered in IDDM. ${ }^{25}$ IGFBP-1 appears to be an inhibitor of IGF-I bioactivity and its concentrations are reciprocally regulated by insulin. ${ }^{26}$ Inadequate insulin concentrations overnight lead to a rise in IGFBP-1 and a fall in IGF-I bioactivity: the degree of abnormality in IGFBP-1 can be directly correlated with $\mathrm{HbA}_{1}$ values. ${ }^{25} 27$

Increasing insulin doses to achieve concentrations necessary for suppression of IGFBP-1 may only lead to unacceptable hypoglycaemia without necessarily suppressing growth hormone secretion. During puberty the very high growth hormone concentrations may also lead to accelerated ketogenesis and contribute to the rapid decompensation and diabetic ketoacidosis which result from poor compliance.

\section{Growth and pubertal development}

Low circulating IGF-I concentrations and reduced bioactivity in IDDM could lead to abnormalities of pubertal growth. Severe abnormalities are now infrequent but the pubertal growth spurt may be blunted particularly in girls. ${ }^{28}$ In early studies, sexual maturation was also delayed in many children with IDDM, but this is now rare although a dissociation between pubarche and adrenarche has been reported. ${ }^{29}$ Menstrual irregularities appear to be more common in adolescents with IDDM and may be related to low concentrations of sex hormone binding globulin. ${ }^{30}$

Growth problems are often more severe in adolescent girls with IDDM and other sex differences can be demonstrated. Glycaemic control as judged by $\mathrm{HbA}_{1}$ is often worse in boys during early puberty and in girls during later puberty. ${ }^{1}$ The tendency to put on excessive weight is also more common in late adolescent girls and cannot entirely be explained by disordered eating habits and differences in exercise patterns. ${ }^{31}$ Further studies of the endocrinology of puberty are needed to explain these sex differences and to understand the well documented effects of puberty on the rate of development of diabetic microangiopathic complications.

\section{Conclusions}

Pubertal development is accompanied by rapid growth and an almost doubling of lean body mass. The provision of adequate nutrition and appropriate insulin requirements in adolescents with IDDM is therefore a major challenge. The insulin dose should be increased, either in line with pubertal development or growth, ${ }^{32}$ and requirements may reach $1.5-2.0 \mathrm{units} / \mathrm{kg} / \mathrm{day}$. It is important, however, to be aware of the risks of over insulinisation overnight and it must be remembered that insulin requirements fall back to prepubertal concentrations at the end of the teenage years. Failure to reduce insulin requirements in the late adolescent girls may aggravate weight gain.

Multiple injection treatment not only offers greater advantages for the adolescent but also provides a logical way of delivering basal insulin requirements during puberty. However, treatment with pen injectors will not necessarily improve glycaemic control and overnight insulin profiles may be far from satisfactory. ${ }^{21}$ Continuous subcutaneous insulin delivery has not proved acceptable in adolescents with IDDM and the development by the pharmaceutical industry of more stable long acting insulins should be encouraged. Finally direct attempts to reduce growth hormone secretion without compromising growth might have a place in the treatment of the adolescent with IDDM. Poor compliance during adolescence should not be unexpected, given the rigours of the diabetic regimen. It is therefore important that good compliance is rewarded by an improvement in glycaemic control, normal growth and development and a reduction in the risks of diabetic complications.

Department of Paediatrics,

D B DUNGER

John Radcliffe Hospital,

Headington,

Oxford $O X 39 D U$

1 Sargeant DT, Achtenberg J, Davis JE. Increased haemogloblin $A_{\mathrm{lc}}$ in insulin dependent diabetes during puberty. Diabetes 1980;29 (suppl 2):177A.

2 Blethen SL, Sargeant DT, Whitlow MG, Santiago JV. Effect of pubertal stage and recent blood glucose control on plasma somatomedin-C in chlidren with insulin-dependent diabetes mellitus. Diabetes 1981;30:868-72.

3 Mann NP, Johnston DI. Total glycosylated haemoglobin $\left(\mathrm{HbA}_{1}\right)$ levels in diabetic children. Arch Dis Child 1982;57:434-7.

4 Tattersall RB, Lowe J. Diabetes in adolescence. Diabetologia 1981;20:517-23. Goldstein DE, Hoeper M. Management of diabetes during adolescence: mission impossible? Clinical Diabetes 1987:5:1-9.

6 Smith CP, Dunger DB, Williams AJK, et al. Relationship between insulin, insulin growth factor $I$ and dehydroepiandrosterone sulfate concentrations during childhood, puberty, and adult life. $\mathcal{f}$ Clin Endocrinol Metab 1989;68:932-7.

7 Bloch CA, Clemons P, Sperling MA. Puberty decreases insulin sensitivity. $\mathcal{F}$ Pediatr 1987;110:481-7.

8 Smith CP, Archibald HR, Thomas JM, et al. Clin Endocrinol (Oxf) 1988;28:7-14.

9 Amiel SA, Sherwin RS, Simonson DC, Lauritano AA, Tamborlane WV. Impaired insulin action in puberty. A contributing factor to poor glycaemic control in adolescents with diabetes. $N$ Engl F Med 1986;315:215-9.

10 Amiel SA, Caprio S, Sherwin RS, Pleeve G, Haymond MW, Tamborlane WV. Insulin resistance of puberty: a defect restricted to peripheral glucose metabolism. I Clin Endocrinol Metab 1991;72:277-82.

11 Hindmarsh PC, Matthews DR, Brook CGD. Growth hormone secretion in children determined by time series analysis. Clin Endocrinol (Oxf) 1988;29: 35-44.

12 Delemarre-Van de Waal HA, Wennick JMB, Odink RJH. Gonadotrophin and growth hormone secretion throughout puberty. Acta Paediatr Scand (Suppl) 1991;372:26-31.

13 Edge JA, Dunger DB, Matthews DR, Gilbert JP, Smith CP. Increased overnight growth hormone concentrations in diabetes compared with normal adolescents. $\mathcal{F}$ Clin Endocrinol Metab 1990;71:1356-62.

14 Hindmarsh P, Di Silvio L, Pringle PJ, Kurt\% AB, Brook CGD. Changes in serum insulin concentration during puberty and their relationship to growth herum insulin concentration during puberty and

15 Arslanian SA, Heil BV, Becker DJ, Drash AL. Sexual dimorphism in insulin sensitivity in adolescents with insulin-dependent diabetes mellitus. F Clin sensitivity in adolescents with in

16 Rizza RA, Mandarino L, Gerich JE. Effects of growth hormone on insulin action in man: mechanisms of insulin resistance, impaired suppression of glucose production and impaired stimulation of glucose utilisation. Diabetes 1982;31:663-9.

17 Bratusch-Marrain PR, Smith D, De Fronzo RA. The effect of growth hormone on glucose metabolism and insulin secretion in man. $\mathcal{F}$ Clin Endocrinol Metab 1982;55:973-82.

18 Beaufrere B, Beylot M, Met; C, et al. Dawn phenomenon in type 1 (insulindependent) diabetic adolescents: influence of nocturnal growth hormone secretion. Diabetologia 1988;31:607-11.

19 Edge JA, Matthews DR, Dunger DB. The dawn phenomenon is related to overnight growth hormone release in adolescent diabetics. Clin Endocrino (Oxf) 1990;33:729-37.

20 Mann NP, Johnston DI. Improvement in metabolic control in diabetic adolescents by the use of increased insulin dose. Diabetes Care 1984;7:460-4.

21 Edge JA, Matthews DR, Dunger DB. Failure of current insulin-regimens to meet the overnight requirements of adolescents with insulin-dependent meet the overnight requirements of ad
diabetes. Diabetes Res 1990;15:109-12.

22 Whincup G, Milner RDG. Prediction and management of nocturnal hypoglycaemia in diabetes. Arch Dis Child 1987;62:333-7.

23 Press M, Caprio S, Tamborlane MW, et al. Pituitary response to growth hormone-releasing hormone in IDDM. Abnormal responses to insulin and hyperglycaemia. Diabetes $1992 ; 41: 17-21$.

24 Gerich JE. Glucose counter-regulation and its impact on diabetes mellitus. Diabetes 1988;37:1608-17.

25 Batch JA, Baxter RC, Werther G. Abnormal regulation of insulin-like growth factor binding proteins in adolescents with insulin-dependent diabetes mellitus. F Clin Endocrinol Metab 1991;73:964-8.

26 Taylor AM, Dunger DB, Preece MA, et al. The growth hormone independen insulin-like growth factor I binding protein BP-28 is associated with serum insulin-like growth factor I inhibitory bioactivity in adolescent insulindependent diabetes. Clin Endocrinol (Oxf 1990;32:229-39.

27 Holly JMP, Dunger DB, Edge JA, Smith CP, Chard T, Was JAH. Insulinlike growth factor binding protein-1 levels in diabetic adolescents and their relationship to metabolic control. Diabetic Med 1990;7:618-23.

28 Salardi S, Cacciari E, Ballardini D, et al. Relationship between growth factors (Somatomedin-C and growth hormone) and body development, metabolic (Somatomedin-C and growth hormone) and body development, metabolic control, and retinal chanetes 1986;35:832-6.
Diabe

29 Cohen HN, Paterson KR, Wallace AM, Beastall GH, Manderson WG MacCuish AC. Dissociation of adrenarche and gonadarche in diabetes mellitus. Clin Endocrinol (Oxf) 1984;20:717-24.

30 Holly JMP, Dunger DB, Edge JA, et al. Sex hormone binding globulin levels in adolescents with diabetes mellitus. Diabetic Med (in press).

31 Peveler RC, Fairburn CG, Boller I, Dunger DB. Eating disorders in adolescents with insulin-dependent diabetes mellitus: a controlled study. Diabetes Care (in press).

32 Hindmarsh PC Mathews DR, Di Silvio L, Kurtz AB, Brook CGD. Relationship between height velocity and fasting insulin concentrations. Arch Dis Child 1988;63:655-66. 